\title{
Memantine Effects on Verbal Memory in Fragile X-associated Tremor/Ataxia Syndrome (FXTAS): a Double-Blind Brain Potential Study
}

\author{
Jin-Chen Yang*, 1,2,9, Yu-Qiong Niu' ${ }^{1,2,9}$, Christa Simon ${ }^{1,2}$, Andreea L Seritan ${ }^{3}$, Lawrence Chen ${ }^{1,4}$, \\ Andrea Schneider ${ }^{5,6}$, Shayan T Moghaddam ${ }^{1,7}$, Paul J Hagerman ${ }^{5,8}$, Randi J Hagerman ${ }^{5,6}$ and \\ John M Olichney*, , 2
}

\begin{abstract}
'Center for Mind and Brain, University of California Davis, Davis, CA, USA; ${ }^{2}$ Department of Neurology, University of California Davis, School of Medicine, Sacramento, CA, USA; ${ }^{3}$ Department of Psychiatry and Behavioral Sciences, University of California Davis, School of Medicine, Sacramento, CA, USA; ${ }^{4}$ Department of Psychology, University of California Davis, Davis, CA, USA; ${ }^{5}$ Medical Investigations of Neurodevelopmental Disorders (MIND) Institute, University of California Davis, School of Medicine, Sacramento, CA, USA; ${ }^{6}$ Department of Pediatrics, University of California Davis, School of Medicine, Sacramento, CA, USA; ${ }^{7}$ College of Biological Sciences, University of California Davis, Davis, CA, USA;

${ }^{8}$ Department of Biochemistry and Molecular Medicine, University of California Davis, Davis, CA, USA
\end{abstract}

\begin{abstract}
Older FMRI premutation carriers may develop fragile X-associated tremorlataxia syndrome (FXTAS), a neurodegenerative disorder manifesting cognitive deficits that often subsequently progress to dementia. To date, there is no specific treatment available for FXTAS. Studies have demonstrated the premutation-associated overactivation of glutamatergic receptors in neurons. Memantine, a NMDA receptor antagonist approved for treatment of Alzheimer's disease, thus was tested in the first placebo-controlled, double-blind, randomized clinical trial in FXTAS. Prior event-related brain potential (ERP) studies in FXTAS found reduced N400 repetition effect, a glutamate-related electrophysiological marker of semantic priming, and verbal memory processes. This substudy of the randomized clinical trial of memantine in FXTAS sought to use the N400 repetition effect to evaluate effects of chronic memantine treatment on verbal memory. Subsequent recall and recognition memory tests for the experimental stimuli were administered to characterize verbal memory. Data from 4 I patients who completed the I-year memantine trial (2I on memantine) and also completed longitudinal ERP studies were analyzed. Results showed treatment-associated benefits on both cued-recall memory and N400 repetition effect amplitude. Importantly, improvement in cued recall was positively correlated with amplitude increase of the N400 repetition effect. The placebo group, in contrast, displayed a significant reduction of the N400 repetition effect after I year. These results suggest that memantine treatment may have beneficial effects on verbal memory in FXTAS. Additional studies of memantine, perhaps in combination with other therapeutic agents, appear warranted, as symptomatic treatments and neuroprotective treatments are both needed for this recently recognized neurodegenerative disorder.
\end{abstract}

Neuropsychopharmacology (20I4) 39, 2760-2768; doi:I0.1038/npp.20I4.I22; published online 2 July 2014

\section{INTRODUCTION}

The fragile $\mathrm{X}$ mental retardation 1 (FMR1) gene premutation is common in the general population $(1: 151-209$ females, 1:430-468 males; Seltzer et al, 2012; Tassone et al, 2012a). Thus, FMR1 premutation-associated disorders have a significant impact on society. FMR1 premutation carriers

* Correspondence: Dr J-C Yang, Center for Mind and Brain, University of California Davis, School of Medicine, 267 Cousteau Place, Davis, CA 956I8-54I2, USA, Tel: 530-297-4429, Fax: 530-297-4400, E-mail: jchyang@ucdavis.edu or Dr JM Olichney, Center for Mind and Brain, University of California Davis, School of Medicine, 267 Cousteau Place, Davis, CA 956I8-54I2, USA, Tel: 530-297-4429, Fax: 530-297-4400, E-mail: jmolichney@ucdavis.edu

${ }^{9}$ These authors contributed equally to this work.

Received 8 February 2014; revised 29 April 2014; accepted 8 May 2014; accepted article preview online 29 May 2014 over age 50 may develop fragile $\mathrm{X}$-associated tremor/ataxia syndrome (FXTAS), a neurodegenerative disorder characterized by intention tremor, cerebellar gait ataxia, neuropathy, and cognitive deficits in executive function, attention, memory, and visual-spatial processing (Brega et al, 2008; Hagerman et al, 2001; Hagerman and Hagerman, 2013; Jacquemont et al, 2003). Radiological abnormalities, including gray matter loss in the cerebellum and the frontal cortex, white matter (WM) diseases (eg, the characteristic MRI WM hyperintensities in the middle cerebellar peduncles-the 'MCP sign') are common in FXTAS (Brunberg et al, 2002; Hashimoto et al, 2011; Wang et al, 2012). The pathological hallmark of FXTAS is the presence of eosinophilic intranuclear inclusions in both the nervous system and other tissues (Greco et al, 2002; Hunsaker et al, 2011). It has been suggested that the FMR1 mRNA toxic gain-of-function is the pathogenic molecular mechanism of 
neurodegeneration in FXTAS (Hagerman, 2013; Jacquemont et al, 2007; Willemsen et al, 2011).

Abnormal neuronal response to glutamate has been demonstrated in the FMR1 premutation. Specifically, the premutation was linked to glutamatergic receptor dependent long-term potentiation (LTP) reduction and long-term depression (LTD) increase (Hunsaker et al, 2012), as well as a clustered burst firing pattern and imbalanced excitatoryinhibitory (ie, glutamate-GABA) neurotransmission in hippocampal neurons (Cao et al, 2012) of the FMR1 premutation mouse model. Furthermore, Liu et al (2012) reported significantly increased response to glutamate in human induced pluripotent stem cell-derived neurons harboring the premutation expansion.

To date, no specific treatment has been proven effective for FXTAS. Memantine, an uncompetitive antagonist of $\mathrm{N}$ methyl-D-aspartate (NMDA) glutamate receptor approved for the treatment of moderate-to-severe AD (Reisberg et al, 2003), has been suggested to be of therapeutic benefit in neurological disorders associated with overactivation of glutamate receptors, including Parkinson disease and Huntington disease (Lipton, 2006). Given the premutation-associated glutamatergic abnormalities, the high prevalence of both $\mathrm{AD}$ pathology (Tassone et al, 2012b) and parkinsonism (Apartis et al, 2012) among premutation carriers, we hypothesized that memantine would improve cognitive and/or motor symptoms in FXTAS patients. Anecdotal evidence and at least one case report have suggested that FXTAS symptoms may be ameliorated by memantine (Ortigas et al, 2010). A recently published report from the first placebo-controlled, double-blind, randomized clinical trial conducted in FXTAS showed no significant treatment effects on clinical and neuropsychological outcome measures including intention tremor severity, executive function, verbal learning/memory, and working memory (Seritan et al, 2014). In the current substudy of the memantine trial, we utilized event-related brain potentials (ERPs) to detect treatment effects on neural processing, and to test if ERPs might be more sensitive to treatment effects than conventional behavioral and clinical measures used in the randomized clinical trial.

Consisting primarily of summed postsynaptic excitatory and inhibitory potentials (EPSPs and IPSPs) (Nunez and Srinivasan, 2006), ERPs may provide a noninvasive and cost-effective measure of synaptic dysfunction in neurological disorders (eg, Luck et al, 2011; Olichney et al, 2011). Our prior ERPs study in FXTAS found marked attenuation of the N400 repetition effect (Olichney et al, 2010) -an established electrophysiological index of semantic priming and other verbal memory processes sensitive to amnestic mild cognitive impairment (MCI) and early AD (Kutas and Federmeier, 2011; Olichney et al, 2006; 2008). This study also observed an inverse correlation between FMR1 mRNA level and N400 amplitude. In depth recording studies of human hippocampus, the NMDA receptor antagonist ketamine has been shown to severely disrupt N400 amplitude (Grunwald et al, 1999). Therefore, the N400 repetition effect could be a useful biomarker of abnormal glutamatergic signaling and synaptic dysfunction in human FMR1 premutation carriers with FXTAS.

The present study used a word repetition paradigm to elicit and modulate the N400 and P600 ERP components
(Olichney et al, 2000; 2010) to investigate the effects of chronic memantine treatment on verbal memory processes in FXTAS. The P600 is a late positive component (LPC), which has been linked to episodic/declarative memory processes and is particularly sensitive to incipient $\mathrm{AD}$ (Olichney et al, 2006; 2008; 2013).

\section{PATIENTS AND METHODS}

\section{Participants}

Participants were individuals with FXTAS enrolled in a comprehensive research study at the Medical Investigation of Neurodevelopmental Disorders (MIND) Institute, University of California Davis (UCD), between September 2007 and August 2012. All participants gave informed consent for protocols approved by the UCD Institutional Review Board. FMR1 CGG repeat lengths were quantified in all subjects using previously described procedures (Tassone et al, 2008). FXTAS was diagnosed following published criteria (Bacalman et al, 2006; Jacquemont et al, 2003). Inclusion criteria were definite, probable, or possible FXTAS. Exclusion criteria included inability to tolerate memantine, renal insufficiency, unwillingness to participate for a year, or current memantine treatment. For the main memantine trial, 94 patients out of a total of 205 screened were eligible to participate. Randomization to either placebo or memantine was done by the UCD pharmacy, and was blinded to all study personnel, investigators, and participants until the end of the trial period. Among 34 participants who completed 1-year memantine treatment and 36 who completed 1-year placebo study, 28 from each group (all native English speakers) participated in the word repetition/ERP experiment. In the memantine group, seven patients were excluded from further analyses for the following reasons: four did not return for the 1-year follow-up ERP study, one had started memantine before the first ERP recording, and two had unusable EEG data due to excessive artifacts (described below). In the placebo group, eight participants were excluded due to: four did not return for the 1-year follow-up ERP study, one had a deep-brain stimulator (DBS), and three had unusable EEG data due to excessive artifacts. Therefore, 21 participants in the memantine group and 20 in the placebo group were included in the final data analyses presented here. Comparisons between the current subset and all participants in the main clinical trial found no significant group differences in age, CGG repeats, FXTAS diagnosis or FXTAS stage $(0.08 \leqslant t$ 's $\leqslant 1.33, \quad 0.19 \leqslant p$ 's $\leqslant 0.94)$, except for educational level (All $=15.4 \pm 2.8$ years, the ERP subset $=14.2 \pm 2.6$ years; $t=2.0, p=0.05)$.

\section{Intervention}

Identical appearing tablets containing either memantine or placebo were provided by Forest Pharmaceuticals at no cost. Titration started with $5 \mathrm{mg} /$ day for one week, increasing by $5 \mathrm{mg}$ each week, until the full maintenance dose of $10 \mathrm{mg}$ twice per day was achieved by day 22. Complete medication lists of each participant were reviewed for possible interactions with memantine. Participants were instructed to keep all other medications unchanged for the duration of the study. 


\section{Neuropsychological Testing}

Each participant's verbal memory was assessed with the California Verbal Learning Test (CVLT) (Delis et al, 1987). Executive functioning was evaluated with the Behavioral Dyscontrol Scale (BDS, a well-validated nine-item test measuring the intentional control of simple voluntary motor behavior) (Grigsby and Kaye, 1996) and the Controlled Oral Word Association Test (COWAT) (DesRosiers and Kavanaugh, 1987).

\section{Word Repetition ERP Experiment}

Electroencephalogram (EEG) and ERP recordings were made during a semantic category decision/word repetition task performed at both the baseline visit and the 1-year follow-up.

Procedure. Participants were fit with an electrode cap and seated $100 \mathrm{~cm}$ from a video monitor. Category statements were read aloud by an experimenter, each followed $(\sim 1 \mathrm{~s}$ later) by a target word visually presented in the center of the monitor (duration $=300 \mathrm{~ms}$, visual angle $=0.4^{\circ}$ ). Participants were instructed to not respond or move for $3 \mathrm{~s}$ following the target word, then to say the word seen and a 'yes' or 'no' judgment indicating whether the word fit with the preceding category statement (congruous trial) or not (incongruous trial). EEG sessions consisted of three blocks of 144 trials, each block lasting slightly over $20 \mathrm{~min}$.

Stimuli. The stimuli were 216 spoken phrases each describing a category (eg, 'a body of water'), and followed by an associated target word. Categories and target words were selected with the aid of published norms and local norms based on administered questionnaires. Half of the targets (congruous words) were medium-typicality category exemplars (eg, 'river' for 'a body of water'). The other half of the targets, matched to congruous targets in length and word frequency, were concrete nouns that were incongruous with their preceding categories (eg, 'visitor' for 'part of a watch').

Participants were randomly assigned to one of three counterbalanced stimulus lists, which included 36 congruous category-target pairs presented once, 36 presented twice, 36 presented three times, and equal numbers of incongruous pairs in the same repetition manners, giving a total of 432 trials. Therefore, half of the stimuli were congruous and half were incongruous, and half were new, whereas half were repeats. Repeated targets always followed the same category statement as in the initial presentation. For category-target pairs repeated once, the lag between the first and second presentations was $0-3$ intervening trials (spanning 10-40s). For pairs repeated twice, the lag for both second and third presentations was 10-13 intervening trials $(\sim 100-140 \mathrm{~s})$.

Electrophysiological recording. Thirty two (32)-channel EEG was recorded. Tin electrodes embedded in an elastic electrode cap were placed at midline $(\mathrm{Fz}, \mathrm{Cz}, \mathrm{Pz}, \mathrm{POz})$, lateral frontal $(\mathrm{F} 3 / 4, \mathrm{~F} 7 / 8, \mathrm{FC} 1 / 2, \mathrm{FP} 1 / 2)$, temporal (T5/6), parietal (P3/4, $\mathrm{CP} 1 / 2)$, and occipital sites (O1/2, $\mathrm{PO} 7 / 8)$, defined by the International 10-20 System. Additional electrodes included bilateral pairs approximating Broca's area (BL), Wernicke's area (WL), and their right hemisphere homologs (BR and WR, respectively), and an electrode pair at $33 \%$ of the interaural distance lateral to $\mathrm{Cz}$ over the superior temporal lobe (L41, R41). Interelectrode impedance was maintained below $5 \mathrm{k} \Omega$. All scalp electrodes were referenced online to the left mastoid and rereferenced offline to the average of both mastoids. Eye movements were monitored by electrooculogram (EOG) recorded with four electrodes (one beneath and one at the outer canthus of each eye). The EEG was amplified and digitized by a Nicolet SM 2000 amplifier with bandpass of $0.016-100 \mathrm{~Hz}$, and a sampling rate of $250 \mathrm{~Hz}$.

Subsequent memory tests for target words. Immediately following the EEG recording, three unanticipated subsequent memory tests (free recall, cued-recall, and multiplechoice recognition) were administered in that order. In the free recall task, participants were asked to write down as many target words seen in the ERP experiment as they can remember. A list of 40 written category statements (22 from congruous trials and 18 from incongruous trials) were provided in the cued-recall test, and subjects were instructed to fill in the target word presented after a given category statement, or to provide the 'first word that comes to mind' if they could not recall the associated target word. The multiple-choice recognition task consisted of the same 40 category statements, each followed by the associated target word and five foils never presented during the experiment.

\section{Data Analysis}

The treatment effects on subsequent memory performance changes (1 year-baseline) were examined by ANCOVA with the within-subject factor of visit, between-subjects factor of treatment, and covariate of gender (because FXTAS is an $\mathrm{X}$-chromosome-related disorder and there are well-established gender differences in the clinical expression of FXTAS (Hagerman and Hagerman, 2013)).

Continuous EEG data were segmented into epochs of $1024 \mathrm{~ms}$ duration (starting at $100 \mathrm{~ms}$ before the target word onset until $924 \mathrm{~ms}$ poststimulus onset). Epochs contaminated with artifacts such as blinks, horizontal eye movements, excessive muscle activity, or amplifier blocking were rejected from further data analyses (mean rejection rate $=49.1 \%$, no differences between groups or visits, $p$ 's $>0.75)$. Artifact-free epochs were averaged by experimental condition to produce ERP waveforms.

Mean amplitude (within 300-550 ms time window) and $50 \%$ fractional area latency of the N400 component were quantified, for four conditions separately (ie, congruous new/old words, incongruous new/old words). To reduce inter-individual variability, we focused our analyses on two experimental effects: the N400 congruity effect (ERPs to incongruous new words minus congruous new words), and the N400 repetition effect (ERPs to incongruous new words minus incongruous old words). The $\mathrm{P} 600$ repetition effect was also calculated by subtracting ERPs to congruous old words from congruous new words in the $550-800 \mathrm{~ms}$ time window. Repeated-measures ANOVA with the betweensubjects factor of treatment, and within-subjects factors of visit and electrode were performed on N400 and P600 data 
Table I Baseline Non-ERP Measures: Mean (SD)

\begin{tabular}{|c|c|c|c|}
\hline & $\begin{array}{c}\text { Memantine } \\
(N=2 I)\end{array}$ & $\begin{array}{l}\text { Placebo } \\
(N=20)\end{array}$ & $\begin{array}{c}P \\
\text { (T-tests) }\end{array}$ \\
\hline Age & $62.1(10.0)$ & $64.7(8.5)$ & 0.39 \\
\hline Female $(N)$ & 10 & 6 & 0.25 \\
\hline Education & I 5.4 (2.5) & $14.2(2.4)$ & 0.14 \\
\hline MMSE & $28.3(3.9)$ & $28.5(1.8)$ & 0.81 \\
\hline CGG repeats & $87.4(16.0)$ & $84.4(17.5)$ & 0.60 \\
\hline FXTAS stage & $2.9(1.0)$ & $3.3(1.0)$ & 0.20 \\
\hline CVLT long delay & $9.6(3.1)$ & $9.1(4.1)$ & 0.70 \\
\hline $\begin{array}{l}\text { CVLT short } \\
\text { delay }\end{array}$ & $9.3(2.7)$ & $8.3(4.1)$ & 0.39 \\
\hline CVLT list A I-5 & $43.8(10.4)$ & $42.8(12.1)$ & 0.79 \\
\hline BDS & I 6.7 (4.3) & $14.9(3.5)$ & 0.20 \\
\hline COWAT & $40.7(18.6)$ & $33.7(13.1)$ & 0.18 \\
\hline
\end{tabular}

Abbreviations: BDS, Behavioral Dyscontrol Scale; COWAT, Controlled Oral Word Association Test; CVLT, California Verbal Learning Test (free recall scores); MMSE, Mini-Mental State Examination.

with 26 scalp electrodes (excluding FP1/2). The Greenhouse-Geisser correction was used to correct for violations of sphericity, and adjusted $p$-values of $<0.05$ were considered significant.

Pearson correlations were tested between the subsequent memory changes (1 year-baseline) and the $\mathrm{N} 400$ repetition effect changes (baseline-1 year). Because the N400 is a negative component, reversing the direction of subtraction made positive values represent increased $\mathrm{N} 400$ repetition effect amplitude after 1 year. Composite N400 amplitude and latency measures averaged from a right posterior cluster of five electrodes (P4, T6, WR, O2, and PO8) were used in correlational analyses.

\section{RESULTS}

\section{Participant Characteristics at Baseline Visit}

Table 1 summarizes participant characteristics at the baseline visit. The two groups (active treatment, placebo) had no significant differences in age, gender, education level, FXTAS disease stage, or FMR1 CGG repeat length. No group differences at baseline were found in verbal memory (as evaluated by the CVLT and subsequent memory tests for the target words), or executive function (measured by the BDS and COWAT) either.

\section{Subsequent Memory for Target Words}

The changes on subsequent memory tests from baseline to the 1-year follow-up visit were calculated for each participant (Table 2). Although both groups showed somewhat better memory at the 1-year visit, likely due to practice effects, the memantine group exhibited subtle yet statistically significant improvements on the cued-recall test for target words compared with the placebo group (congruous target words only: memantine $=2.95$, placebo $=0.60$, $F_{(1,38)}=5.30, \quad p=0.027$; congruous and incongruous target words together: memantine $=3.13$, placebo $=0.70$,
Table 2 Subsequent Memory Scores and Changes $(\Delta=\mid$ Year - Baseline): Mean (SD)

\begin{tabular}{|c|c|c|c|c|c|c|c|}
\hline & \multicolumn{3}{|c|}{$\begin{array}{l}\text { Memantine } \\
(N=21)\end{array}$} & \multicolumn{3}{|c|}{$\begin{array}{l}\text { Placebo } \\
(N=20)\end{array}$} & \multirow[t]{2}{*}{$p^{*}$} \\
\hline & Baseline & I Year & $\Delta$ & Baseline & I Year & $\Delta$ & \\
\hline FR—both & $13.2(10.4)$ & $14.7(13)$ & 1.48 & |4.| (9.7) & $16.6(\mid 1)$ & 2.45 & 0.76 \\
\hline FR-congruous & $10.7(8.1)$ & I 1.7 (9.8) & 1.05 & $12.3(8.3)$ & $13.9(9.5)$ & 1.60 & 0.86 \\
\hline CR—both & I $5.7(4.6)$ & I $8.8(4.0)$ & 3.13 & $17.8(3.7)$ & I 8.5 & 0.70 & $0.037 *$ \\
\hline CR_congruous & I5.2 (4.0) & $18.1(3.1)$ & 2.95 & $16.9(3.4)$ & $17.5(4.2)$ & 0.60 & 0.027 * \\
\hline$M C$-both & $28.3(9.6)$ & $32.2(6.5)$ & 3.90 & $27.6(8.8)$ & 29.0 & 1.45 & 0.21 \\
\hline MC - congruous & | 8.5 (5.5) & $20.1(2.0)$ & 1.62 & | $8.9(4.0)$ & $19.2(3.2)$ & 0.30 & 0.29 \\
\hline
\end{tabular}

Abbreviations: $C R$, cued-recall, $F R$, free recall, $M C$, multiple-choice.

$p$-Values are for the visit $\times$ treatment interactions from ANCOVAs controlling for gender). ${ }^{*} p<0.05$.

$\left.F_{(1,38)}=4.67, p=0.037\right)$, indicating treatment benefits on associative memory retrieval. No group differences were found for the free recall or multiple-choice recognition tests. Also, there were no significant group differences for changes on the main measures of the CVLT (learning list A trials 1-5, discriminability, delayed free, or cued-recall).

\section{ERP Results}

Figure 1 depicts the grand average ERP waveforms to the new target words (congruous and incongruous). Both groups displayed N400 congruity effects (with larger negativities elicited by incongruous than congruous new words) at both visits (memantine: baseline $=$ $-0.83 \pm 1.96 \mu \mathrm{V}, 1$ year $=-1.46 \pm 2.01$; placebo: baseline $=$ $-0.86 \pm 2.25 \mu \mathrm{V}, 1$ year $=-0.43 \pm 1.77)$.

Figure 2 presents the N400 repetition effect (incongruous new - incongruous old ERPs; for superimposed ERPs to the two conditions, see Supplementary Figure S1). Analysis of N400 repetition effect mean amplitude from 26 scalp electrode sites showed a significant visit $\times$ treatment $\times$ electrode three-way interaction $\left(F_{(5.5,213.7)}=2.26, p=0.04\right.$, $\left.\eta^{2}=0.055\right)$. Thus, further analyses were carried out with a cluster of five right posterior electrodes (P4, T6, WR, O2, and PO8), which have robust N400 activity in normals, according to both the literature (as reviewed in Kutas and Federmeier, 2011) and data of the current study (Figure 2). Analyses with this right posterior electrode cluster revealed a significant visit $\times$ treatment interaction $\left(F_{(1,39)}=7.58\right.$, $\left.p=0.009, \eta^{2}=0.163\right)$. Follow-up within-group comparisons showed a significant decrease of the N400 repetition effect amplitudes after 1 year in the placebo group (baseline $=-1.44 \pm 1.38 \mu V, 1$ year $=-0.34 \pm 1.60 ; F_{(1,19)}$ $=5.31, p=0.033)$, and an insignificant trend for an amplitude increase in the memantine group (baseline $=$ $-1.16 \pm 2.08 \mu V, \quad 1 \quad$ year $=-1.66 \pm 1.53 ; \quad F_{(1,20)}=2.18$, $p=0.16)$. Indeed, the topographic maps of the 1 -year visit showed no negativities for the placebo group in the early portion (300-400 ms) of the $\mathrm{N} 400$ time window, indicating a delayed and markedly diminished N400 repetition effect after the 1-year observational period (Figure 2d). 


\section{Effects of memantine on verbal memory in FXTAS}

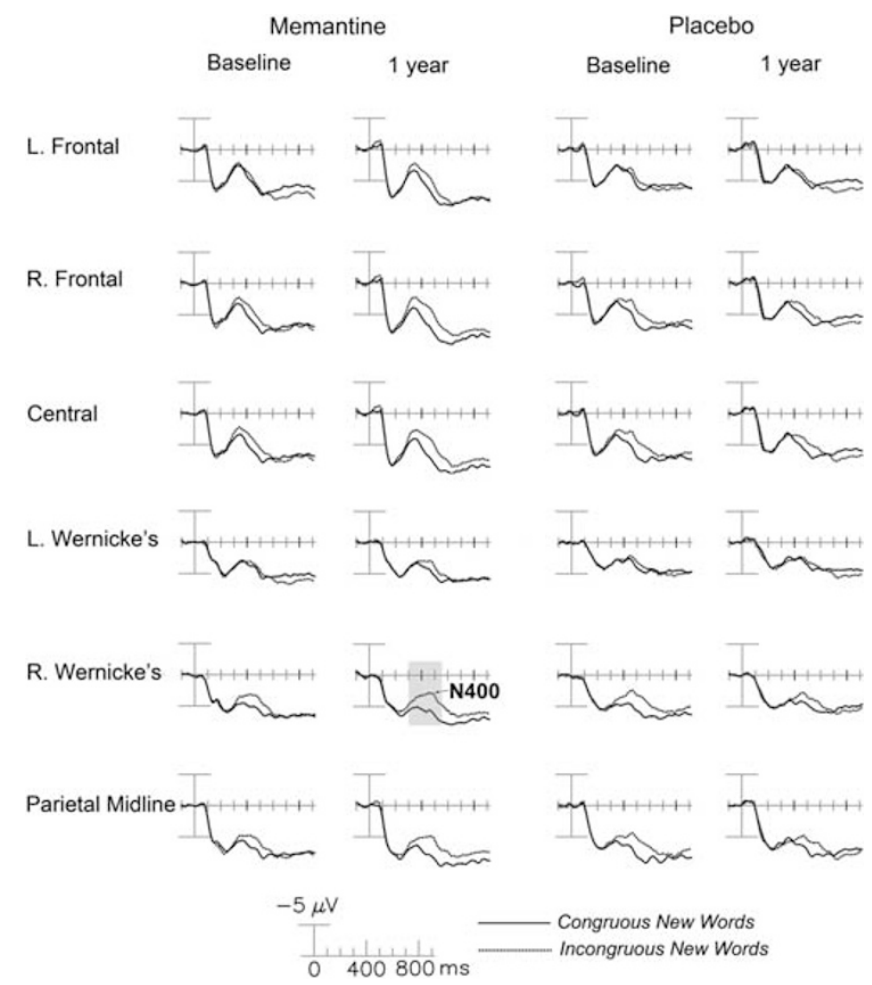

Figure I The N400 to new words (congruous and incongruous targets separately, measured from 300-550 ms time window as illustrated on the right Wernicke's channel) at six electrodes from fronto-central (FCI/2, Cz), temporal (WL/WR), and parietal (Pz) scalp sites, plotted by treatment group and visits. The memantine group showed an insignificant increase in N400 congruity effect amplitude (new incongruous - congruous words, Baseline $=-0.83 \pm 1.96 \mu \mathrm{V}, \mathrm{I}$ year $=-1.46 \pm 2.0 \mathrm{I} ; p=0.1 \mathrm{I})$ after I year of treatment, whereas the placebo group displayed an insignificant reduction over the period (Baseline $=-0.86 \pm 2.25 \mu \mathrm{V}$, । year $=$ $-0.43 \pm 1.77 ; p=0.31)$.

Correlational tests revealed that increased $\mathrm{N} 400$ repetition effect amplitudes (averaged across the five right posterior channels) were associated with improved cued-recall scores for the congruous target words (1 year-baseline; Figure 3) across all subjects $(r=0.35, p=0.027)$, with insignificant correlations in the same direction both in the memantine group $(r=0.31, p=0.177)$ and the placebo group $(r=0.22$, $p=0.345)$. A marginal significance $(r=0.31, p=0.051)$ was found for the correlation between the N400 repetition effect amplitude enhancement and the improved cued-recall performance for both type of target words (ie, congruous and incongruous combined). A significant correlation was also observed between longer latency (change from baseline to 1-year follow-up) of the N400 repetition effect (averaged across the right posterior cluster) and decreased performance (baseline to 1-year follow-up) on the CVLT longdelay cued-recall test $(r=-0.46, p=0.028)$.

Correlations with both CGG repeat length and FXTAS stage were observed for the CVLT cued-recall measure at baseline $(r=-0.35, p=0.044$ and $r=-0.43, p<0.01$, respectively). No correlations between either the CGG repeat length or FXTAS stage with the N400 repetition effect amplitude (either at baseline or changes over 1 year) were present $(p$ 's $>0.16)$.

No significant treatment effects were observed for the latency of either the N400 congruity effect or the N400 repetition effect ( $p$ 's $>0.65$ ). Also, there was no visit $x$ treatment interaction present for the $\mathrm{P} 600$ repetition effect $(F=1.62, p=0.21)$, even though the P600 repetition effect at baseline was correlated with subsequent memory performance at the same visit (eg, $r=0.53, p<0.001$ for free recall scores and a composite P600 repetition effect amplitude averaged from six centro-parietal electrodes).

\section{DISCUSSION}

In this substudy of the first placebo-controlled, doubleblind, randomized clinical drug trial in FXTAS, patients receiving 1 year of memantine treatment demonstrated benefits on both cued-recall memory performance and the ERP N400 repetition effect. Larger increases of the N400 repetition effect in the memantine group were associated with stronger improvements in cued-recall memory performance. The placebo group displayed statistically significant reduction of the N400 repetition effect after 1 year, whereas the treated group showed preservation of the N400 repetition effect, with an insignificant trend for larger N400 repetition effect amplitudes after 1 year on memantine. Verbal memory of the placebo group stayed relatively stable after 1 year, but this group showed less improvement in cued-recall scores than the treated group, who had a larger learning effect. Consistent with the results from all FXTAS patients who completed the 1 year memantine trial (Seritan et al, 2014), no treatment effects on the CVLT were observed in this ERP substudy. Perhaps memantine has a specific effect on memory retrieval aided by specific cues (eg, the same category statements seen in the ERP experiment), given the established evidence for the involvement of hippocampal NMDA receptor in associative memory recall (eg, Nakazawa et al, 2002). This treatment effect is modest and appears limited to cued-recall, with no significant improvements on free recall or recognition memory. The negative finding concerning the multiplechoice recognition test could be due to the possibility that the participants can perform the task relying primarily on the item familiarity/recollection rather than the associative binding with the context (ie, the category statements).

Several factors could have contributed to the positive treatment effects found in the present study, but not in the parent study (Seritan et al, 2014). First, ERPs offer exquisite temporal resolution and a real-time objective measure of summated synaptic currents, which have been related to specific cognitive processes. Second, the ERP experiment was carried out in a well-controlled electrophysiological lab setting, and learning occurred in a sound-proof chamber, which minimized interference from other stimuli. Also, it should be noted that the ERP target words were presented visually and the congruous words were preceded by supportive semantic contexts, whereas the CVLT uses auditory word lists with no supporting semantic context provided. Finally, the shared glutamatergic mediating mechanisms underlying both the FXTAS neurodegeneration and the N400 component likely helped the present study to detect subtle treatment effects of memantine.

The N400 repetition effect is a well-established electrophysiological marker of semantic priming, and of verbal memory processes such as repetition priming (ie, facilitated 


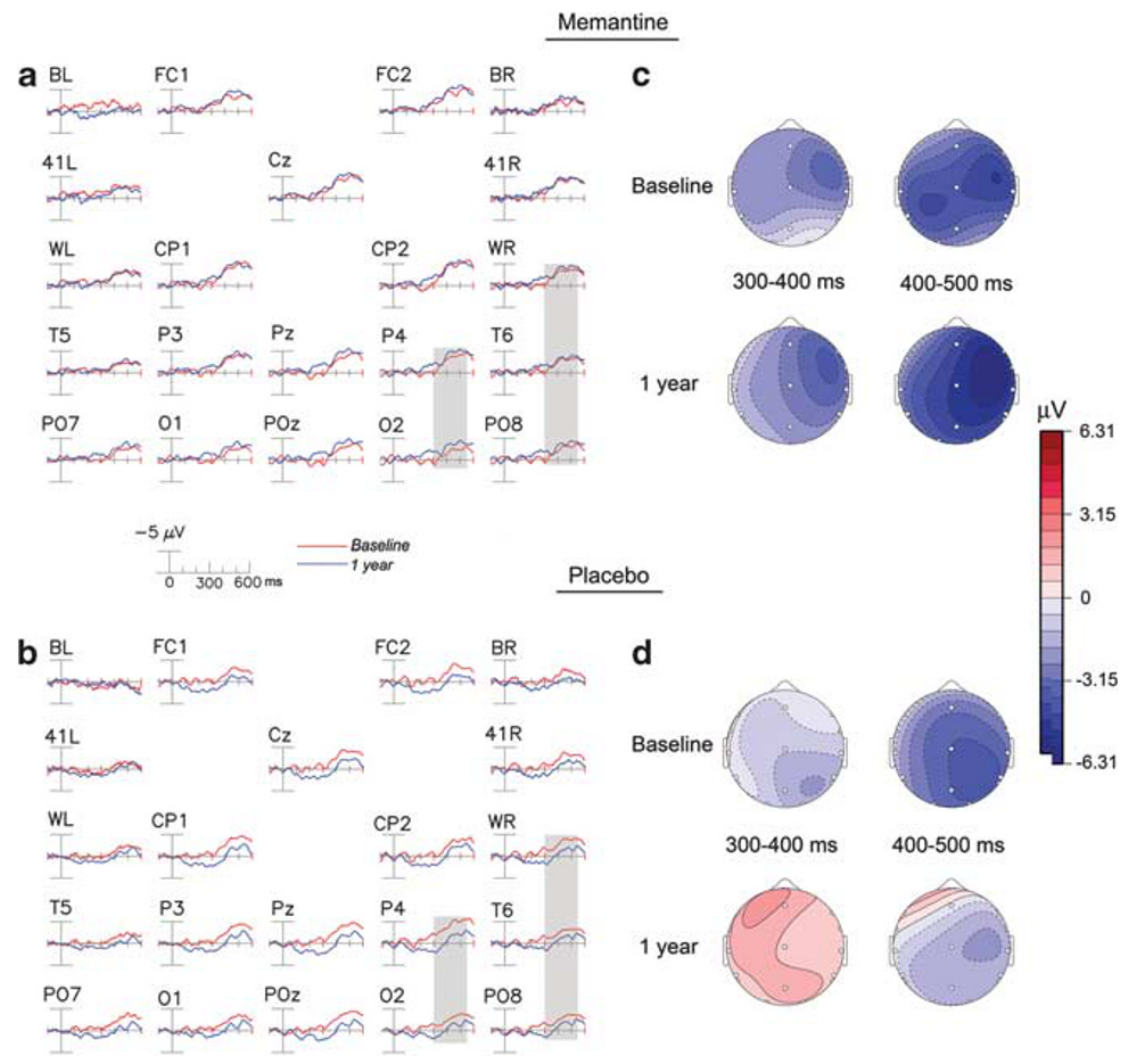

Figure 2 (a) and (b): The N400 repetition effects, ie, the difference waveforms (300-550 ms) generated by subtracting ERPs to incongruous old target words from ERPs to incongruous new target words, within each group. Robust treatment effects were demonstrated within the shaded right posterior cluster consisting of five electrodes (visit $\times$ treatment interaction: $F_{(1,39)}=7.58, p=0.009, \eta^{2}=0.163$ ), with significant decreases (mean $=1.1 \mu \mathrm{V}$ ) in the placebo group ( $p=0.033$ ) and an insignificant trend for $\mathrm{N} 400$ repetition effect amplitude increases (mean $=0.54 \mu \mathrm{V})$ in the memantine group $(p=0.16)$. (c) and (d): Topographic distribution of the N400 repetition effects across the early (300-400 ms) and late (400-500 ms) time windows, plotted by treatment group and visits, within each group.

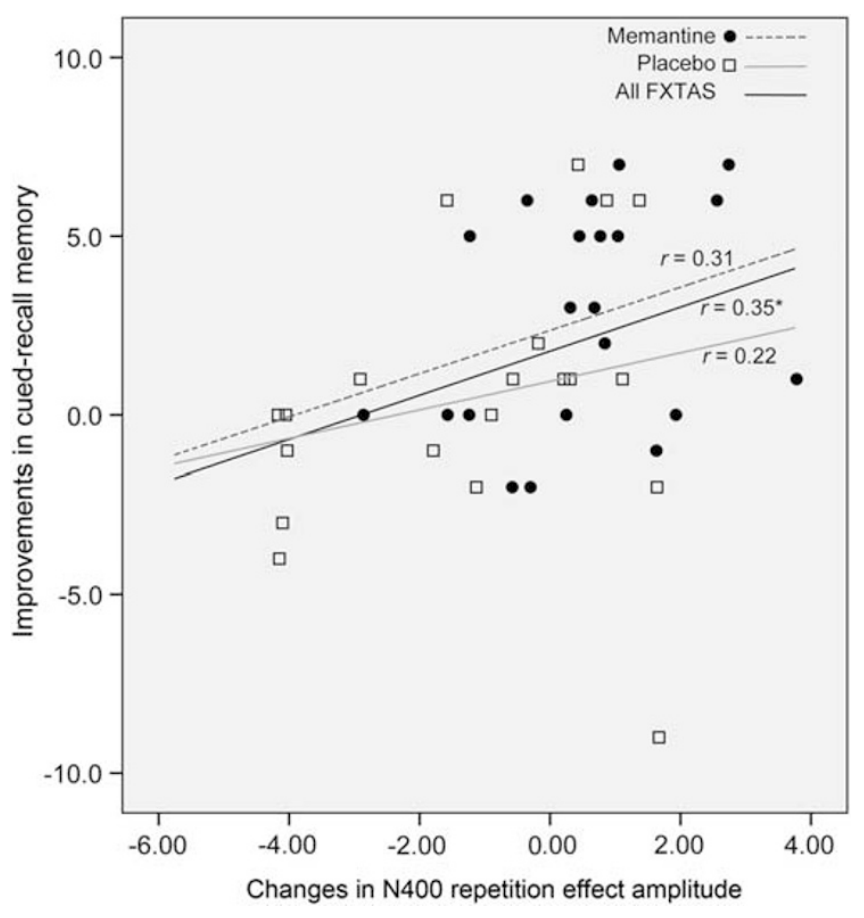

Figure 3 Correlations between the changes in the composite N400 repetition effect amplitude ( $\mathrm{UV}$, averaged from the right posterior cluster of five electrodes) and the improvements on subsequent cued-recall memory test. responses to repeated stimuli) (Olichney et al, 2000). As described in the introduction section, glutamatergic signaling is critical for the generation of the N400 ERP component (Grunwald et al, 1999). Meanwhile, glutamatergic signaling abnormalities, such as the clustered burst firing pattern (Cao et al, 2012) have been observed in hippocampal neurons of a FMR1 premutation mouse model. Our ERP results support the view that treatment with the uncompetitive NMDA receptor antagonist memantine improves glutamatergic signaling (Lipton, 2006) in FXTAS patients. This uncompetitive antagonist can block excessive activation of the NMDA receptors while leaving normal physiological activity relatively intact. It also is thought to increase the signal-to-noise ratio in glutamatergic signaling (eg, Danysz and Parsons, 2003). This is a likely mechanism by which these individuals' incidental learning and associative memory processes (ie, cued-recall) were improved/facilitated.

The memantine-associated behavioral improvements in the subsequent cued-recall memory for the experimental stimuli suggest treatment benefits not only on implicit memory, but also may impact declarative/explicit memory. Although most of our prior ERP studies using this word repetition paradigm have not found significant correlations between the N400 repetition effect and memory, some of these were underpowered to find moderate correlations, and/or had restricted ranges of memory scores. Several 
other investigators have hypothesized and/or found relationships between the $\mathrm{N} 400$ and aspects of declarative memory (see Kutas and Federmeier, 2011 for a systematic review). For example, Helmstaedter et al (1997) reported that the N400 was related to verbal learning (rather than retention) abilities on the basis of subdural recordings over lateral temporal cortex of well-characterized epileptic patients.

Consistent with the familiarity/recollection model of recognition memory (Yonelinas et al, 2010), two ERP components have been linked to different aspects of recognition processes: the frontal N400 (FN400) reflecting familiarity and the late positive component (LPC) indexing recollection ( $\mathrm{Yu}$ and Rugg, 2010). Although the semantic N400 and the more anteriorly-distributed FN400 are thought to represent different cognitive processes, they may overlap with each other in some experimental paradigms (ie, those that elicit both conceptual priming and familiarity). A large body of literature has linked the P600, a late positive component, to declarative memory and recollection processes. Although not reflecting identical cognitive processes, the P600/LPC elicited by word repetition and the well-known episodic LPC have very similar scalp topography and both index episodic memory processes (Olichney et al, 2013; Rugg and Curran, 2007). Several of our past studies have also found strong correlations between the $\mathrm{P} 600$ repetition effect amplitude and verbal memory performance (Olichney et al, 2000; $2006 ; 2008 ; 2013)$. In the present study, the $\mathrm{P} 600$ repetition effect amplitude at baseline was significantly associated with subsequent memory test scores, but the improvements in subsequent cued-recall memory were correlated with the changes in the N400 repetition effect rather than P600 repetition effect, possibly due to the relative small and statistically insignificant changes observed in the P600 repetition effect amplitude.

Executive dysfunction has been suggested to be the fundamental cognitive deficit in FXTAS (Brega et al, 2008; Grigsby et al, 2008). Our prior studies have demonstrated a reduced frontal P300 ERP component in FXTAS patients (Yang et al, 2013a; 2013b) and older female carriers without FXTAS (Yang et al, 2013b), which was associated with frontal executive dysfunction as measured by instruments such as the BDS. Even though memantine has been reported to ameliorate cognitive speed on executive functioning tests in PDD or DLB (Aarsland et al, 2009), the memantine treatment did not show significant effects on P300 measures in these FXTAS patients (unpublished observation), indicating that the effects of memantine are primarily on memory processes, but not executive or motor function in FXTAS individuals. In line with this notion, a study of a harmaline-induced tremor mouse model found that memantine has weaker anti-tremor effect, but stronger neuroprotective efficacy against neuron loss, compared with ethanol (Iseri et al, 2011).

In summary, 1-year memantine treatment has effects on cued memory retrieval in FXTAS patients, probably through regulating the FMR1 mRNA associated glutamatergic signaling abnormalities, but no noticeable benefits on executive dysfunction. Limitations of the present study include: (1) limited power to detect small effect sizes due to a modest sample size; (2) possible type I error due to lack of adjustment for multiple statistical comparisons. Therefore, the modest treatment effects we found on cued-recall memory and the $\mathrm{N} 400$ repetition effect are in need of independent replication. Further research trials of memantine and combinational therapies with other therapeutic agents for this neurodegenerative disorder appear warranted, especially considering the lack of any proven therapy to date. Cao et al (2012) suggested allopregnanolone, a positive modulator of $\mathrm{GABA}_{\mathrm{A}}$ receptors, as a candidate therapeutic agent to ameliorate the abnormal mGluR1/5 signaling in FMR1 premutation neurons. Also, in a Drosophila model of FMR1 premutation, Qurashi et al (2012) found that phospholipase A2 (PLA2) inhibitors can ameliorate the premutation CGG repeat-mediated neuronal toxicity. Future clinical trials testing the additive and/or synergic effects and safety of the combination of memantine with allopregnanolone, PLA2, or other anti-ataxia and anti-tremor medications are suggested. This study also demonstrated that welldesigned cognitive ERP/EEG tests might offer sensitive means to detect intervention effects that may not be evident in standard behavioral or clinical assessments.

\section{FUNDING AND DISCLOSURE}

Dr Yang reports no disclosures. Dr Niu reports no disclosures. Ms Simon reports no disclosures. Dr Seritan received funding form NIH grants RL1AG032115, R01MH078041, and R01MH078041-04S1 and currently receives funding from R01HD036071 and from the Substance Abuse and Mental Health Administration grant 1U79SM060482-01. Mr Chen reports no disclosures. Dr Schneider receives funding from NIH grants HD036071, PR101054, MC22641, MH078041, MH086854-01A1, $\mathrm{MH087720-02.} \mathrm{She} \mathrm{also} \mathrm{received} \mathrm{funding} \mathrm{for} \mathrm{a} \mathrm{clinical} \mathrm{drug}$ trial by Neuropharm-NPL-2009-2-FEN-001 in her role as psychologist. Mr Torabi Moghaddam reports no disclosures. Dr Randi Hagerman has received funding from Roche, Novartis, Forest, Seaside Therapeutics, and Curemark for clinical trials in fragile $\mathrm{X}$ syndrome or autism. She has consulted with Novartis and Roche/Genentech about fragile $\mathrm{X}$ treatment studies. She has received funding from NINDS RL1AG032115 for this study. Dr Paul Hagerman receives funding from NIH grants R01 HD040661 and R42 HD078988; at the time of the research, he was also funded by RL1AG032119 and UL1 DE019583. Dr Hagerman holds patents for quantification of CGG repeat number and for measurement of FMRP levels. He has submitted, with Pacific Biosciences, a patent application for SMRT-sequencing methodology. He collaborates with Pacific Biosciences without compensation; he and Pacific Biosciences are corecipients of STTR grant (R42 HD078988) from the NICHD. Dr Olichney receives funding from NIH grants P30AG10129, received funding from grants RO1AG018442, RL1AG032115, and the State of California Alzheimer's Disease Program. $\mathrm{He}$ also receives support from Genentech for a clinical drug trial and has served as a consultant for Lundbeck Pharmaceuticals.

\section{ACKNOWLEDGEMENTS}

We thank all the participants in the study and their families. We would like to thank Flora Tassone Lab for molecular 
characterization, Louise Gane for genetic counseling, Jennifer Cogswell for part of the neuropsychological assessments, Yi Mu, Danh Nguyen, and Kylee Cook for help with data retrieval.

\section{REFERENCES}

Aarsland D, Ballard C, Walker Z, Bostrom F, Alves G, Kossakowski K et al (2009). Memantine in patients with Parkinson's disease dementia or dementia with Lewy bodies: a double-blind, placebocontrolled, multicentre trial. Lancet Neurol 8: 613-618.

Apartis E, Blancher A, Meissner WG, Guyant-Marechal L, Maltete D, De Broucker T et al (2012). FXTAS: new insights and the need for revised diagnostic criteria. Neurology 79: 1898-1907.

Bacalman S, Farzin F, Bourgeois JA, Cogswell J, Goodlin-Jones BL, Gane LW et al (2006). Psychiatric phenotype of the fragile $\mathrm{X}$-associated tremor/ataxia syndrome (FXTAS) in males: Newly described fronto-subcortical dementia. J Clin Psychiatry 67: 87-94.

Brega AG, Goodrich G, Bennett RE, Hessl D, Engle K, Leehey MA et al (2008). The primary cognitive deficit among males with fragile X-associated tremor/ataxia syndrome (FXTAS) is a dysexecutive syndrome. J Clin Exp Neuropsychol 30: 853-869.

Brunberg JA, Jacquemont S, Hagerman RJ, Berry-Kravis EM, Grigsby J, Leehey MA et al (2002). Fragile X premutation carriers: characteristic MR imaging findings of adult male patients with progressive cerebellar and cognitive dysfunction. AJNR Am J Neuroradiol 23: 1757-1766.

Cao Z, Hulsizer S, Tassone F, Tang HT, Hagerman RJ, Rogawski MA et al (2012). Clustered burst firing in FMR1 premutation hippocampal neurons: amelioration with allopregnanolone. Hum Mol Genet 21: 2923-2935.

Danysz W, Parsons CG (2003). The NMDA receptor antagonist memantine as a symptomatological and neuroprotective treatment for Alzheimer's disease: preclinical evidence. Int J Geriatr Psychiatry 18: S23-S32.

Delis D, Kramer J, Kaplan E, Ober B (1987). California Verbal Learning Test. The Psychological Corporation: San Antonio, TX.

DesRosiers G, Kavanagh D (1987). Cognitive assessment in closed head injury: Stability, validity and parallel forms for two neuropsychological measures of recovery. Int J Clin Neuropsyc 9: $162-173$.

Greco CM, Hagerman RJ, Tassone F, Chudley AE, Del Bigio MR, Jacquemont $S$ et al (2002). Neuronal intranuclear inclusions in a new cerebellar tremor/ataxia syndrome among fragile $\mathrm{X}$ carriers. Brain 125: 1760-1771.

Grigsby J, Brega AG, Engle K, Leehey MA, Hagerman RJ, Tassone F et al (2008). Cognitive profile of fragile $\mathrm{X}$ premutation carriers with and without fragile $\mathrm{X}$-associated tremor/ataxia syndrome. Neuropsychology 22: 48-60.

Grigsby J, Kaye K (1996). The Behavioral Dyscontrol Scale: Manual. 2nd edn. BDS: Denver, CO.

Grunwald T, Beck H, Lehnertz K, Blumcke I, Pezer N, Kurthen M et al (1999). Evidence relating human verbal memory to hippocampal N-methyl-D-aspartate receptors. Proc Natl Acad Sci USA 96: 12085-12089.

Hagerman P (2013). Fragile X-associated tremor/ataxia syndrome (FXTAS): pathology and mechanisms. Acta Neuropathol 126: $1-19$.

Hagerman PJ, Hagerman RJ (2013). Advances in clinical and molecular understanding of the FMRlpremutation and fragile X-associated tremor/ataxia syndrome. Lancet Neurol 12: 786-798.

Hagerman RJ, Leehey M, Heinrichs W, Tassone F, Wilson R, Hills J et al (2001). Intention tremor, parkinsonism, and generalized brain atrophy in male carriers of fragile X. Neurology 57: $127-130$.
Hashimoto R, Javan AK, Tassone F, Hagerman RJ, Rivera SM (2011). A voxel-based morphometry study of grey matter loss in fragile X-associated tremor/ataxia syndrome. Brain 134: 863-878.

Helmstaedter C, Kurthen M, Linke DB, Elger CE (1997). Patterns of language dominance in focal left and right hemishpere epilepsies: relation to MRI findings, EEG, sex and age at onset of epilepsy. Brain Cogn 33: 135-150.

Hunsaker MR, Greco CM, Spath MA, Smits AP, Navarro CS, Tassone $\mathrm{F}$ et al (2011). Widespread non-central nervous system organ pathology in fragile $\mathrm{X}$ premutation carriers with fragile $\mathrm{X}$-associated tremor/ataxia syndrome and CGG knock-in mice. Acta Neuropathol 122: 467-479.

Hunsaker MR, Kim K, Willemsen R, Berman RF (2012). CGG trinucleotide repeat length modulates neural plasticity and spatiotemporal processing in a mouse model of the fragile $\mathrm{X}$ premutation. Hippocampus 22: 2260-2275.

Iseri PK, Karson A, Gullu KM, Akman O, Kokturk S, Yardymoglu $M$ et al (2011). The effect of memantine in harmalineinduced tremor and neurodegeneration. Neuropharmacology 61: 715-723.

Jacquemont S, Hagerman RJ, Hagerman PJ, Leehey MA (2007). Fragile- $\mathrm{X}$ syndrome and fragile $\mathrm{X}$-associated tremor/ataxia syndrome: two faces of FMR1. Lancet Neurol 6: 45-55.

Jacquemont S, Hagerman RJ, Leehey M, Grigsby J, Zhang L, Brunberg JA et al (2003). Fragile X premutation tremor/ataxia syndrome: molecular, clinical, and neuroimaging correlates. Am J Hum Genet 72: 869-878.

Kutas M, Federmeier KD (2011). Thirty years and counting: finding meaning in the N400 component of the event-related brain potential (ERP). Annu Rev Psychol 62: 621-647.

Lipton SA (2006). Paradigm shift in neuroprotection by NMDA receptor blockade: memantine and beyond. Nat Rev Drug Discov 5: $160-170$.

Liu J, Koscielska KA, Cao Z, Hulsizer S, Grace N, Mitchell G et al (2012). Signaling defects in iPSC-derived fragile X premutation neurons. Hum Mol Genet 21: 3795-3805.

Luck SJ, Mathalon DH, O'Donnell BF, Hämäläinen MS, Spencer KM, Javitt DC et al (2011). A roadmap for the development and validation of event-related potential biomarkers in schizophrenia research. Biol Psychiatry 70: 28-34.

Nakazawa K, Quirk MC, Chitwood RA, Watanabe M, Yeckel MF, Sun LD et al (2002). Requirement for hippocampal CA3 NMDA receptors in associative memory recall. Science 297: 211-218.

Nunez PL, Srinivasan R (2006). Electric Fields of the Brain: the Neurophysics of EEG. 2nd edn. Oxford University Press: New York, NY.

Olichney JM, Chan S, Wong LM, Schneider A, Seritan A, Niese A et al (2010). Abnormal N400 word repetition effects in fragile $\mathrm{X}$-associated tremor/ataxia syndrome. Brain 133: 1438-1450.

Olichney JM, Iragui VJ, Salmon DP, Riggins BR, Morris SK, Kutas M (2006). Absent event-related potential (ERP) word repetition effects in mild Alzheimer's disease. Clin Neurophysiol 117: 1319-1330.

Olichney JM, Pak J, Salmon DP, Yang J-C, Gahagan T, Nowacki R et al (2013). Abnormal P600 word repetition effect in elderly persons with Preclinical Alzheimer's disease. Cogn Neurosci 4: 143-151.

Olichney JM, Taylor JR, Gatherwright J, Salmon DP, Bressler AJ, Kutas M et al (2008). Patients with MCI and N400 or P600 abnormalities are at very high risk for conversion to dementia. Neurology 70: 1763-1770.

Olichney JM, Van Petten C, Paller KA, Salmon DP, Iragui VJ, Kutas M (2000). Word repetition in amnesia. Electrophysiological measures of impaired and spared memory. Brain 123: 1948-1963.

Olichney JM, Yang JC, Taylor J, Kutas M (2011). Cognitive event-related potentials: biomarkers of synaptic dysfunction 
Effects of memantine on verbal memory in FXTAS

J-C Yang et al

across the stages of Alzheimer's disease. J Alzheimers Dis 26: 215-228.

Ortigas MC, Bourgeois JA, Schneider A, Olichney J, Nguyen DV, Cogswell JB et al (2010). Improving fragile X-associated tremor/ataxia syndrome symptoms with memantine and venlafaxine. J Clin Psychopharmacol 30: 642-644.

Qurashi A, Liu H, Ray L, Nelson DL, Duan R, Jin P (2012). Chemical screen reveals small molecules suppressing fragile $\mathrm{X}$ premutation rCGG repeat-mediated neurodegeneration in Drosophila. Hum Mol Genet 21: 2068-2075.

Reisberg B, Doody R, Stoffler A, Schmitt F, Ferris S, Möbius HJMemantine Study Group (2003). Memantine in moderate-tosevere Alzheimer's disease. N Engl J Med 348: 1333-1341.

Rugg M, Curran T (2007). Event-related potentials and recognition memory. Trends Cogn Sci 11: 251-257.

Seltzer MM, Baker MW, Hong J, Maenner M, Greenberg J, Mandel D (2012). Prevalence of CGG expansions of the FMR1 gene in a US population-based sample. Am J Med Genet B Neuropsychiatr Genet 159B: 589-597.

Seritan AL, Nguyen DV, Mu Y, Tassone F, Bourgeois JA, Schneider A et al (2014). Memantine for fragile X-associated tremor/ataxia syndrome (FXTAS): a randomized, double-blind, placebocontrolled trial. J Clin Psychiatry 75: 264-271.

Tassone F, Greco CM, Hunsaker MR, Seritan AL, Berman RF, Gane LW et al (2012b). Neuropathological, clinical and molecular pathology in female fragile $X$ premutation carriers with and without FXTAS. Genes Brain Behav 11: 577-585.
Tassone F, Iong KP, Tong TH, Lo J, Gane LW, Berry-Kravis E et al (2012a). FMR1 CGG allele size and prevalence ascertained through newborn screening in the United States. Genome Med 4: 100.

Tassone F, Pan R, Amiri K, Taylor AK, Hagerman PJ (2008). A rapid polymerase chain reaction-based screening method for identification of all expanded alleles of the fragile X (FMR1) gene in newborn and high-risk populations. J Mol Diagn 10: 43-49.

Wang JY, Hessl DH, Hagerman RJ, Tassone F, Rivera SM (2012). Age-dependent structural connectivity effects in fragile $\mathrm{x}$ premutation. Arch Neurol 69: 482-489.

Willemsen R, Levenga J, Oostra BA (2011). CGG repeat in the FMR1 gene: size matters. Clin Genet 80: 214-225.

Yang JC, Chan S, Khan S, Schneider A, Nanakul R, Teichholtz S et al (2013a). Neural substrates of executive dysfunction in fragile X-associated tremor/ataxia syndrome (FXTAS): a brain potential study. Cereb Cortex 23: 2657-2666.

Yang JC, Simon C, Niu YQ, Bogost M, Schneider A, Tassone F et al (2013b). Phenotypes of hypofrontality in older female fragile $\mathrm{x}$ premutation carriers. Ann Neurol 74: 275-283.

Yonelinas AP, Aly M, Wang WC, Koen JD (2010). Recollection and familiarity: examining controversial assumptions and new directions. Hippocampus 20: 1178-1194.

Yu SS, Rugg MD (2010). Dissociation of the electrophysiological correlates of familiarity strength and item repetition. Brain Res 1320: $74-84$.

Supplementary Information accompanies the paper on the Neuropsychopharmacology website (http://www.nature.com/npp) 